\title{
Competitive intelligence and international business
}

\author{
Marié-Luce Muller \\ Managing Director and CI Analyst \\ IBIS Business and Information Services \\ mlm@ibis.co.za \\ www.ibis.co.za
}

\section{Introduction}

It would perhaps be apt to start off this year's series of columns on competitive intelligence (CI) by assessing the status quo of CI practices in various countries. A recently published study on CI practices in South Africa by the Bureau of Market Research (BMR) at the University of South Africa confirms earlier research that CI has a key role to fulfil in making business more competitive by enhancing business decision making. In this article, the CI practices in various countries are examined and compared briefly with those in South Africa.

\section{Overview of CI as practised globally}

Competitive intelligence (CI) is one of the fastest growing fields in the business world and is increasingly drawing attention throughout the world (Viviers, Saayman, Calof and Muller 2002). CI is not a new business activity. Meyer (1987) says successful business enterprises have been collecting and using intelligence for centuries but what differentiates early efforts from those at present is the organized nature of modern CI. As more countries are embracing market-based economies, CI is evolving as a world-wide practice with some countries more advanced than others.

Among the leaders in early CI are Japan, Sweden, Israel and the USA. Japan has been known to have gathered innovative technology and sensitive business information over many years. The Japan External Trade Organization, a government institution, is known to be driving the gathering of industrial and economic intelligence (Joyal 1996). In Japan, trading companies or sogo shosha such as Mitsui have set the standard in terms of intelligence gathering and understanding business intelligence as organized information (Meyer 1987). Choate (1990) refers to the intelligence gathering capabilities of Japanese trading companies 'as a vast overseas information collection system' that transmits the information to their headquarters where intelligence analysts transform it into an intelligence product.

Sweden is often referred to in literature as being a leader in CI. Because the Swedes see intelligence as a non-military way to ensure national peace and prosperity, the country has a well-developed CI culture (Calof 1998). The small but significant number of Swedish international companies all share information to work towards strengthening the overall competitive situation. The banks play an important role in this effort and openly admit their role along with the Swedish government and its embassies around the world. The Lund University in Sweden was the first to offer a PhD in CI (www.scip.org). In Sweden, there is a 
handful of companies who provide almost all of Sweden's new products and services and they all work towards this common goal by sharing information. The banks play a vital role in this effort (having formed Upplysnigs Centralen, a CI research company in the 70s), along with the Swedish government and its embassies around the world that quite openly admit their role (MultiQuest).

Sweden is not the only country where CI is formally taught of course. In Japan and France there are government affiliated schools and courses of study dedicated to CI (Kahaner 2006). In South Africa, like in the US and many other countries, students can obtain a master of business administration degree without ever taking a class in CI, but awareness among academics is spreading, albeit slowly.

Although Australia, like South Africa, started later (Bensoussan 2003) than the early leading CI countries, Australian businesses are rapidly adopting CI as a tool to enhance competitiveness. This is also a trend in South Africa where the early experimental CI practices are being replaced by those that are more formal, focused and sophisticated. Bensoussan's assessment (2003) is that while past experimental CI approaches might have been sufficient, current realities call for more structured approaches. This also holds true for South Africa and the challenge of competing in an increasingly complex, competitive and uneven business environment.

\section{Why CI?}

One of the key drivers for the development of CI has been globalization and the complex competitive global environment where countries often compete on an uneven basis. The globalization of interests is no longer limited to multinationals. Any company, even a small, less internationalized one wishing to grow its business, could now look at expanding into exporting and developing operations in various markets. This, however, calls for a different approach to how information is viewed and used, what information needs to focus on and how information could be used to increase knowledge on opportunities and risk. Globalization, therefore, represents a radical change in international business (James 2000).

Globalization has impacted on the nature of information needs of companies. Besides knowledge on new markets, consumers and relevant technologies, expanding into the global market has also meant that companies become dependent on partners, such as distribution agents, and are entering into partnerships where a market entry brings its own challenges in terms of information needs. Assessing and achieving merger and acquisition opportunities requires in-depth profiles as well as assessments of competitors and customers. With an uneven playing field as a reality, there is not the luxury of experimenting with various models and partners. This is substantiated by the recent BMR research into CI practices in South Africa (2007) that has found that one key intelligence requirement is knowledge about potential strategic partners.

Coleman (2007) emphasizes the benefits of CI in the role it plays in making companies 'decision-ready' and able to 'respond early and effectively to events and opportunities'. CI arms companies to become bold and assured in their strategies and aims at giving them a competitive advantage rather than relegating them to a game of catch-up. But then they have to know what to focus on and have the ability to act on the intelligence that is produced by the CI capability.

CI has particular application not only in strategic decision making but also in the areas of sales and marketing, choice of partners and customer relationship management. The true value of CI, if conducted well, lies in its ability to provide a fairly clear picture of the future business environment in which a company operates. Sales forecasting and product demand 
forecasting are perceived to benefit the most (BMR 2007).

\section{Development stages of CI}

Literature shows that some countries, including France, Japan, Sweden and the USA, are more advanced in adopting and using CI but that they also needed a process of development, starting informally and becoming more sophisticated over time. In these countries, CI has earned its rightful place as an acknowledged business discipline and has become a major source of achieving competitive advantage (MultiQuest Consultants).

Various factors influence the development of CI in countries. These include culture, the nature of the economy, the country's competitive position and aspects such as location and a supportive regulatory environment. One possible reason for the differences in CI development in different countries is that in some countries (e.g. France, Israel, Sweden and Canada) the government plays an important role as an intelligence provider for businesses. Governments in these and many other countries are devoting their resources to help their companies develop CI capabilities (Calof 1998). In more secretive societies, such as Korea or countries that went through a stage of being relatively isolated from global competition forces, development was slower (Kim and Kim 2004).

Other reasons for the higher level of CI development in the aforementioned countries include heightened competition in the global marketplace, more advanced and formalized CI training programmes and the extent these countries are involved in international trade.

Early CI practices were more likely to be unstructured, with managers relying on their human resource network to provide them with information and insight into relevant developments. With the Internet, the overload of information that companies experience at present has called for a different approach to managing information for competitive advantage. Before the current, fast pace of the Internet and globalization, formal intelligence processes were rare anywhere in the world and were more haphazard than systematic, structured and routine. Current realities have forced intelligence to the forefront and the sophistication of CI has subsequently increased globally. The Internet means 'immediacy', what has just happened, what is happening right now, and what is about to happen (Coleman 2007).

Late CI adopters, including Korea, China, Australia and South Africa, perhaps share a common lack of urgency, limited participation in the global marketplace and a degree of isolation from the impact of global forces on competitiveness. Company leaders in these and other countries are increasingly realizing the importance of understanding global markets in order to compete and cooperate with their counterparts world-wide and the role CI plays in this. A study by Tao and Prescott (2001) found that Chinese companies also initially started out by having informal experimental CI operations and that practices are still evolving.

As was the case in South Africa, CI in Korea developed over time (Kim and Kim 2004) with external forces being the main drivers of CI needs, practices and developmental stages. Korea however started a CI culture much sooner than South Africa. Leading Chaebol groups in Korea started building formal CI programmes in the early 1980s, and have continuously been improving their CI practices ever since.

Studies into global CI practices show that CI evolves over time and that hurdles and challenges that need to be overcome show similarities across countries and practices. The BMR study (2007) observed that CI practices in South Africa are lacking in certain areas including having the right focus and sufficient intelligence on potential strategic partners and relevant trends. Challenges to the future development of CI in Korea also include getting the 
focus right but there are also unique challenges including getting rid of the secretive nature of CI, improving CI's image and ensuring that the right infrastructure for CI is in place (Kim and Kim 2004). In South Africa, an insufficient choice of accredited academic CI programmes could be regarded as a developmental area that is also relevant in many other countries. Few countries have higher education institutions where CI is taught formally and at graduate level although this is changing in South Africa, albeit slowly. As in South Africa, for example, CI programmes in Australian business schools are rare with only the Macquarie Graduate School of Management and the Sydney Graduate School of Management offering an elective on CI in an MBA programme. Bond University and the University of South Australia teach it as an undergraduate subject in their Bachelor degrees (Bensoussan 2003).

An assessment of the current programmes in CI at South African learning institutions revealed a lack of formal academic programmes. Current programmes are mainly limited to short courses in basic CI principles. At present there are no CI courses presented at secondary schools in South Africa and, although some progress has been made in the development of courses, much still needs to be done. Programmes should also be presented at business schools at MBA level or at least as part of management and leadership training (Viviers and Muller 2004).

\section{Focus areas}

Various studies into global CI practices cite similar key focus intelligence areas. These can be summarized as follows:

- Gain in-depth actionable intelligence on new markets and on how best to enter those markets

- Tracking capabilities of competitors to learn about techniques and strategies that competitors are using to gain and sustain a competitive advantage

- Assessing industry players to gain an understanding of their strategies and strong and weak points

- Knowledge on new markets and customers and how to establish presence there

- Learn where competitors are vulnerable and how to gain the advantage

- Intelligence on relevant laws and regulations that need to be taken into account when conducting business in a particular business environment.

\section{Conclusion}

An interesting observation that can be made after studying the CI practices in various countries is that the role of CI evolves and changes over time. In Korea for example, early CI practices were mainly shaped by environmental forces, such as political/legal, economic, industry, technological and cultural forces and that original shaping forces changed over time to be more technological, economic and service orientated in nature.

Another observation is that in the countries studied there is a trend towards more formal CI practices and a degree of sophistication in CI practices over time. Furthermore, CI is becoming more recognized for the role it could potentially play in enhancing competitiveness.

CI seems also to have shed the early yoke of being branded a secretive, unethical and an illegal business practice. In South Africa, it is hardly a secret that if companies do not practice $\mathrm{CI}$ in some or other form, they will struggle to become or remain successful. In fact, among managers there is widespread recognition of the value of CI to enhance profits. The fact that CI is being practised widely has led to companies speaking more openly about practising CI. The study on CI in Korea suggests however that there are places where CI is 
still regarded as a secretive activity.

Studying the CI practices in other countries provides valuable insight into the challenges that might be encountered and, more importantly, the lessons that could be learnt that would benefit local companies and industries. In the next three articles, in-depth studies of the CI practices in a few select countries will be reported.

\section{References}

Bensoussan, B. 2003. Australian CI practices: a comparison with the US. Journal of Competitive Intelligence and Management 1(3).

Calof, J. 1998. Increasing your CIQ: the competitive intelligence edge. The 1998 Economic and Technology Development Journal of Canada. [Online]. Available at: http://www.edco.on.ca/journal/item22.htm. (Accessed 4 March 2004).

Choate, P. 1990. Agents of influence: how Japan's lobbyists in the United States manipulate America's political and economic system. New York.

Coleman, B. 2007. Competitive intelligence - real-time knowledge management. The Data Administration Newsletter (TDAN.com). [Online]. Available at:

http://www.tdan.com/edatt_publisher.htm.

James, S. 2000. Focus on global competitive intelligence. Information Outlook. (February).

Joyal, P. 1996. Industrial espionage today and information wars of tomorrow. 19th National Information Systems Security Conference. Baltimore, USA. October.

Kahaner, L. 2006. Have you heard the following statements? Have you thought or said them yourself? [Online]. Available at: www.kahaner.com/ci_statements.shtml.

Kim, K. and Kim, S. 2004. Competitive intelligence in Korea. Journal of Competitive Intelligence and Management 2(3).

Meyer, H. 1987. Real-world intelligence: organized information for executives.

MultiQuest Consultants [No date]. [Online]. Available at: http://www.mqcinc.com (Accessed 8 March 2007).

Tao, Q. and Prescott, J. 2001. China: competitive intelligence practices in an emerging market environment. Competitive Intelligence Review 11(4):65-78.

Society of Competitive Intelligence Professionals [No date]. [Online]. Available at: http://www.scip.org. (Accessed 10 March 2007). Viviers, W. and Muller, M-L. 2004. The evolution of competitive intelligence in South Africa: early 1980s-2003. Journal of Competitive Intelligence and Management 2(3):53-69.

Viviers, W., Saayman, A., Calof, J.L. and Muller, M-L. 2002. Competitive intelligence practices: a South African study. South African Journal of Business Management 33(3):2737

\section{About the author:}


Marié-Luce Muller is a consulting CI analyst with IBIS Business and Information Services (Pty) Ltd, a leading Pretoria-based CI consultancy. She has a distinguished career in CI. Her primary experience lies in assisting companies in honing their CI capabilities. She also performs tracking and scanning activities on behalf of companies. Marié-Luce has published many articles on competitive intelligence (CEO Magazine, Finance Week, Business Week, Beeld, Die Burger and the South African Journal of Business Management), including an article on South Africa as an emerging CI player, which was published in an international publication of the Society of Competitive Intelligence Professionals (SCIP). She has also published a series of booklets on CI (Nuts and Bolts business series, published by Knowledge Resources) and is a member of a research team participating in an international study of CI practices among exporting companies. Previously, she was involved in research into the status of CI practices in South Africa. A member of SCIP, she holds a postgraduate degree from the University of Stellenbosch.

\section{Disclaimer}

Articles published in SAJIM are the opinions of the authors and do not necessarily reflect the opinion of the Editor, Board, Publisher, Webmaster or the Rand Afrikaans University. The user hereby waives any claim he/she/they may have or acquire against the publisher, its suppliers, licensees and sub licensees and indemnifies all said persons from any claims, lawsuits, proceedings, costs, special, incidental, consequential or indirect damages, including damages for loss of profits, loss of business or downtime arising out of or relating to the user's use of the Website. 
ISSN 1560-683X

Published by InterWord Communications for Department of Information and Knowledge Management, University of Johannesburg 